\title{
An Overview of the Korean Intermittent Exotropia Multicenter Study by the Korean Association for Pediatric Ophthalmology and Strabismus
}

Dae Hee Kim¹, Seung-Hee Baek ${ }^{1}$, Hee-young Choi² , Dong Gyu Choi ${ }^{3}$, Dong Cheol Lee ${ }^{4}$, Se-Youp Lee ${ }^{4}$, Han Woong Lim ${ }^{5}$, Hyun Taek Lim ${ }^{6}$, Won Yeol Ryu, Hee Kyung Yang ${ }^{8}$, Key Hwan Lim for Korean Association for Pediatric Ophthalmology and Strabismus

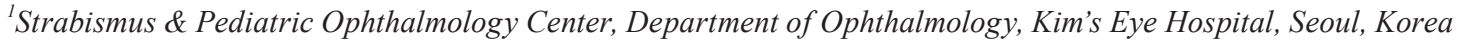
${ }^{2}$ Department of Ophthalmology, Pusan National University School of Medicine, Busan, Korea

${ }^{3}$ Department of Ophthalmology, Kangnam Sacred Heart Hospital, Hallym University College of Medicine, Seoul, Korea ${ }^{4}$ Department of Ophthalmology, Keimyung University School of Medicine, Daegu, Korea

${ }^{5}$ Department of Ophthalmology, Hanyang University School of Medicine, Seoul, Korea

${ }^{6}$ Department of Ophthalmology, Asan Medical Center, University of Ulsan College of Medicine, Seoul, Korea

${ }^{7}$ Department of Ophthalmology, Dong-A University College of Medicine, Busan, Korea

${ }^{8}$ Department of Ophthalmology, Seoul National University Bundang Hospital, Seoul National University College of Medicine, Seongnam, Korea

${ }^{9}$ Department of Ophthalmology, Ewha Womans University College of Medicine, Seoul, Korea

The Korean Intermittent Exotropia Multicenter Study (KIEMS), which was initiated by the Korean Association of Pediatric Ophthalmology and Strabismus, is a collaborative multicenter study on intermittent exotropia in Korea. The KIEMS was designed to provide comprehensive information, including subjective and objective findings of intermittent exotropia in a large study population. A total of 65 strabismus specialists in 53 institutions contributed to this study, which, to date, is one of the largest clinical studies on intermittent exotropia. In this article, we provide a detailed methodology of the KIEMS to help future investigations that may use the KIEMS data.

Key Words: Intermittent exotropia, Korean Association of Pediatric Ophthalmology and Strabismus, Korean Intermittent Exotropia Multicenter Study, Methods, Multicenter study

\section{Introduction}

Received: June 19, $2021 \quad$ Final revision: July 1, 2021

Accepted: July 5, 2021

Corresponding Author: Key Hwan Lim, MD, PhD. Department of Ophthalmology, Ewha Womans University College of Medicine, 1071 Anyangcheon-ro, Yangcheon-gu, Seoul 07985, Korea. Tel: 82-2-2650-5659, Fax: 82-2-2654-4334, E-mail: limkh@ewha.ac.kr
The Korean Intermittent Exotropia Multicenter Study (KIEMS), which was initiated by the Korean Association of Pediatric Ophthalmology and Strabismus, is a nationwide, cross-sectional study to investigate intermittent exotropia in Korea. Intermittent exotropia is the most common form of strabismus in pediatric populations in Korea [1,2] and in several other Asian countries [3-6]. It is a clinical 
entity that shows diverse and variable clinical characteristics. There have been numerous studies that described clinical characteristics of intermittent exotropia, but the findings of those studies were insufficient in providing comprehensive information about the condition due to relatively small sample sizes, a lack of detailed questions on disease history or observations in daily life, and inadequate investigative methods and parameters. This study aimed to describe overall symptomatologic information and clinical features of intermittent exotropia in a large population of Korea.

\section{KIEMS Overview}

\section{Study summary}

This study was a retrospective, observational, cross-sectional, and multicenter study. The participants were recruited from March 1, 2019 to February 29, 2020 by 65 strabismus specialists in 53 institutions, of which secondary or tertiary referral centers accounted for $98.1 \%$, in Korea. This study protocol conformed to the tenets of the Declaration of Helsinki and was approved by the institutional review board of each institution. Informed consent was waived due to the retrospective nature of the study. Questionnaires and examination forms were pre-distributed to the investigators for the standardization of collected data. Each investigator collected the questionnaires and examination forms from every first visited intermittent exotropia patient. The data collection was conducted in accordance with the Personal Information Protection Act. After private information in the questionnaires and examination forms were anonymized and encrypted (e.g., intended deletion of some privacy information to keep reproducing prior to data collection), the questionnaires and examination forms were collected by the KIEMS committee and were handled centrally.

\section{Inclusion criteria}

This study included patients diagnosed with 8 prism diopters or more exodeviation at distant or near fixation, regardless of age or fusion control (including exophoria, intermittent exotropia, and constant exotropia). We excluded patients with congenital ocular anomalies or ocular myop- athies. Patients with limitation of ocular motility resulting in incomitant strabismus, including neurologic or paralytic disorders, previous ocular surgical history, including strabismus and visually affecting surgeries, or any conditions affecting the central visual acuity, including anterior segment abnormality, cataracts, retinal diseases, or blepharoptosis (ocular sensory disorders), were excluded. When a patient was suspected to visit multiple institutions, only the first reported data were used to avoid redundancy.

\section{Questionnaires}

This study collected disease-related information from patients or their guardians using questionnaires. The questions were as follows: the reason for visiting the specialist; the first person who noticed associated symptoms; onset of symptoms; frequency of manifested exotropia noticed per day; guardian's recognition of the exotropia manifestations (direction of deviation and ocular dominance) [7]; associated symptoms (abnormal head posture, photophobia, glare, reading difficulty, headache, ocular pain, micropsia, or blurring) [8-10]; frequency of diplopia (at distant or near viewing conditions) [11]; history of occlusion therapy (duration, frequency, and laterality); history of wearing glasses; systemic diseases; history of developmental delay; childbirth history (type of delivery, gestational age, and birth weight) [12]; perinatal medical conditions (birth complications); and history of exotropia in parents and siblings (including a history of strabismus surgery history) [12]. Questionnaires were constructed as a combination of open-ended and multiple-choice questions. An English version of the questionnaire was provided in Supplement 1.

\section{Ophthalmic exams}

Ophthalmic exams were done by the investigators according to pre-distributed standardized guidelines and formats. The ophthalmic exams included best corrected visual acuity and cycloplegic refraction data. Strabismus angles were measured at distant $(6 \mathrm{~m})$ and near fixation $(33 \mathrm{~cm})$ in primary, right-, left-, up-, and down-gaze, and right and left head-tilted position using alternate prism and cover test. If the exotropic angle at distant fixation measured 10 prism diopters or more than at near fixation, exotropic angles at distant and near fixation in the primary position were remeasured after one eye was covered with a patch 
Table 1. Distribution of study population according to age and sex

\begin{tabular}{lrrr}
\hline Age $($ yr $)$ & \multicolumn{1}{c}{ Male } & \multicolumn{1}{c}{ Female } & Total \\
\hline Less than 5 & $689(40.5)$ & $1,014(59.5)$ & 1,703 \\
5 to $<10$ & $1,298(49.4)$ & $1,330(50.6)$ & 2,628 \\
10 to $<15$ & $380(58.1)$ & $274(41.9)$ & 654 \\
15 to $<20$ & $97(61.8)$ & $60(38.2)$ & 157 \\
20 to $<40$ & $99(58.6)$ & $70(41.4)$ & 169 \\
40 to $<60$ & $24(44.4)$ & $30(55.6)$ & 54 \\
60 or more & $5(25.0)$ & $15(75.0)$ & 20 \\
Total & $2,592(48.1)$ & $2,793(51.9)$ & 5,385 \\
\hline
\end{tabular}

Values are presented as number (\%) or number.

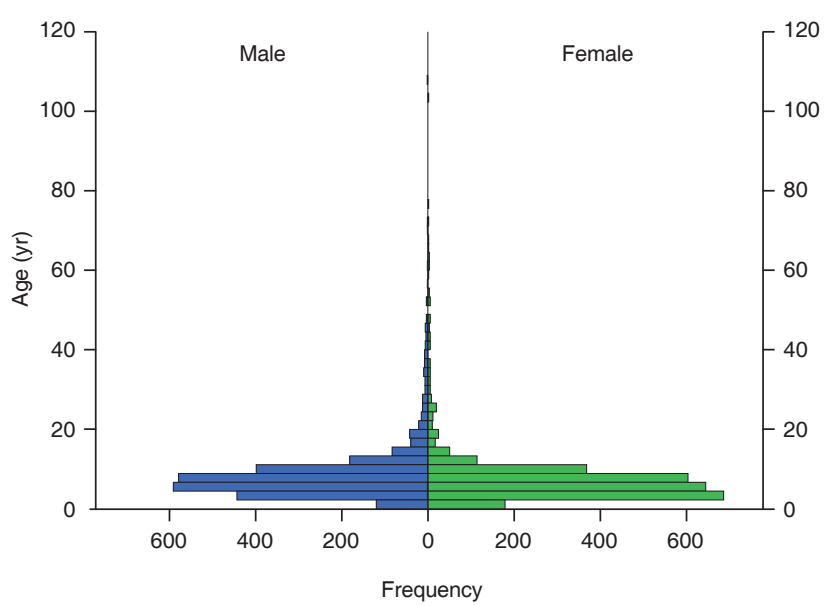

Fig. 1. Study population pyramids. Most of the study participants were in their 1st or 2 nd decade of life. The female participants were found to be younger than the male subjects $(p<0.001$, independent $t$-test).

for 30 minutes to 1 hour (occlusion test of Scobee-Burian) [13]. After the occlusion test, the +3.00 diopter spherical lens test was followed to measure accommodative convergence/accommodation ratio at near fixation [13]. Superior and inferior oblique muscle functions were graded as +1 to +4 for overaction and -1 to -4 for underaction based on the standard photographs [14]. Fusion control was measured both at distant and near fixation, and were graded as "good", "fair", or "poor" [14]. Ocular dominance was also assessed at distant and near fixation conditions. For assessing binocular sensory status, Worth four-dot test was done at $6 \mathrm{~m}$ of distance, and either Titmus stereotest or random-dot stereograms was done at $40 \mathrm{~cm}$ of distance [15]. To investigate the variability of treatment plans among the investigators, investigators were asked to select desirable treatment plans (surgery methods, prescription of glasses, occlusion therapy, or observation plans) for a specific patient. An English version of examination form was provided in Supplement 2.

\section{Study populations}

A total of 5,837 cases were collected. The cases missing essential information (individual-identifying information or deviation angle in primary position, 156 cases) or suspected to be redundant (suspected to visit two or more institutions collecting individual-identifying information, 296 cases) were excluded during the review process by the KIEMS committee. The remaining 5,385 cases were included for comprehensive analysis. Male and female participants were 2,592 (48.1\%) and 2,793 cases (51.9\%), respectively, showing female preponderance, which was similar to a previous study [16]. The mean age of all the included participants was $8.2 \pm 7.6$ years (mean \pm standard deviation). The mean age of the male participants was 8.6 \pm 7.3 years, which was higher than that of female participants (7.8 \pm 7.8 years) (independent $t$-test, $p<0.001$ ). Ninety-five percent of the subjects were under 19 years of age, which meant most patients with intermittent exotropia were diagnosed in their childhood, similar with the findings of a previously reported study [17] population-based cohort. PARTICIPANTS: All pediatric $(<19$ years old. The age distribution of the subjects is depicted in Fig. 1 and Table 1 .

\section{Conclusion}

The KIEMS study is one of the largest clinical studies on intermittent exotropia ever conducted. The study was conducted by experienced strabismus specialists in multiple institutions in Korea, with pre-planned and standardized study protocols. The questionnaires and investigating items covered almost all symptoms and characteristics ever described or reported in intermittent exotropia. Therefore, the KIEMS study can provide objective, detailed, and standardized information about symptomatology and clinical features of intermittent exotropia in Korea. This article can explain the detailed methodology for future research using the KIEMS data. 


\section{Conflict of Interest}

No potential conflict of interest relevant to this article was reported.

\section{Acknowledgements}

The KIEMS study was initiated and financially supported by the Korean Association of Pediatric Ophthalmology and Strabismus.

\section{KIEMS writing committee (listed in alphabetical order of last name)}

Seung-Hee Baek, Hee-young Choi, Dong Gyu Choi, Dae Hee Kim, Dong Cheol Lee, Se-Youp Lee, Han Woong Lim, Hyun Taek Lim, Key Hwan Lim, Won Yeol Ryu, Hee Kyung Yang

\section{Investigator's name (listed in the order of number of patients which investigators contributed)}

Hee-young Choi (Pusan National University), Hyun Taek Lim (Asan Medical Center), Jae Ho Jung (Seoul National University), Seung-Hee Baek (Kim's Eye Hospital), Mi Young Choi (Chungbuk National University), JeongMin Hwang (Seoul National University), Su Jin Kim (Pusan National University), Yeon-hee Lee (Chungnam National University), Sueng-Han Han (Yonsei University), Shin Hae Park (The Catholic University of Korea), HaengJin Lee (Jeonbuk National University), Sook-Young Kim (Daegu Catholic University), Se-Youp Lee (Keimyung University), Hyo Jung Gye (Nune Eye Hospital), So Young Kim (Soonchunhyang University), Sun Young Shin (The Catholic University of Korea), Jihyun Park (Nune Eye Hospital), Won Yeol Ryu (Dong-A University), Hye Sung Park (Siloam Eye Hospital), Dae Hee Kim (Kim's Eye Hospital), Hae Jung Paik (Gachon University), Dong Gyu Choi (Hallym University), Joo Yeon Lee (Hallym University), Hee Kyung Yang (Seoul National University), Shin Yeop Oh (Sungkyunkwan University), Soo Jung Lee (Inje University), Seung Ah Chung (Ajou University), Jin Choi (Inje University), Sei Yeul Oh (Sungkyunkwan University), Mirae Kim (Nune Eye Hospital), Young-Woo Suh (Korea University), Nam Yeo Kang (The Catholic Univer- sity of Korea), Hae Ri Yum (The Catholic University of Korea), Sun A Kim (Sungmo Eye Hospital), Hyuna Kim (Soonchunhyang University), Jinu Han (Yonsei University), Yoonae A. Cho (Nune Eye Hospital), Hyunkyung Kim (Hangil Eye Hospital), Helen Lew (CHA University), Dong Cheol Lee (Keimyung University), Sang Hoon Rah (Yonsei University), Yung-Ju Yoo (Kangwon National University), Key Hwan Lim (Ewha Womans University), Hyosook Ahn (Asan Medical Center), Ungsoo S. Kim (Kim's Eye Hospital), Jung Ho Lee (Daegu Premier Eye Center), Hokyung Choung (Seoul National University), Seong-Joon Kim (Seoul National University), Hyeshin Jeon (Pusan National University), Hyun Jin Shin (Konkuk University), So Young Han (Sungkyunkwan University), Hwan Heo (Chonnam National University), Soochul Park (Saevit Eye Hospital), Songhee Park (Soonchunhyang University), Sung Eun Kyung (Magok Dream Light Eye Clinic), Changzoo Kim (Kosin University), Kyung-Ah Park (Sungkyunkwan University), Eun Hye Jung (Eulji University), Eun Hee Hong (Hanyang University), Han Woong Lim (Hanyang University), Daye Choi (Kim's Eye Hospital), Youn Joo Choi (Hallym University), Nam Ju Moon (Chung Ang University), In Jeong Lyu (Korea Cancer Center Hospital), Soon Young Cho (Dongguk University)

\section{Supplemental Material}

Supplemental materials are available from: https://doi. org/10.3341/kjo.2021.0097.

\section{References}

1. Choi KW, Koo BS, Lee HY. Preschool vision screening in Korea: results in 2003. J Korean Ophthalmol Soc 2006; 47:112-20.

2. Han KE, Baek SH, Kim SH, et al. Prevalence and risk factors of strabismus in children and adolescents in South Korea: Korea National Health and Nutrition Examination Survey, 2008-2011. PLoS One 2018;13:e191857.

3. Matsuo T, Matsuo C. The prevalence of strabismus and amblyopia in Japanese elementary school children. Ophthalmic Epidemiol 2005;12:31-6.

4. Chia A, Dirani M, Chan YH, et al. Prevalence of amblyopia and strabismus in young Singaporean Chinese children. 
Invest Ophthalmol Vis Sci 2010;51:3411-7.

5. Pan CW, Zhu H, Yu JJ, et al. Epidemiology of intermittent exotropia in preschool children in China. Optom Vis Sci 2016;93:57-62.

6. Goseki T, Ishikawa H. The prevalence and types of strabismus, and average of stereopsis in Japanese adults. Jpn $J$ Ophthalmol 2017;61:280-5.

7. Han KE, Lim KH. Discrepancies between parental reports and clinical diagnoses of strabismus in Korean children. $J$ AAPOS 2012;16:511-4.

8. Campos EC, Cipolli C. Binocularity and photophobia in intermittent exotropia. Percept Mot Skills 1992;74(3 Pt 2):1168-70.

9. Hirota M, Kanda H, Endo T, et al. Relationship between reading performance and saccadic disconjugacy in patients with convergence insufficiency type intermittent exotropia. Jpn J Ophthalmol 2016;60:326-32.

10. Hirota M, Kanda H, Endo T, et al. Binocular coordination and reading performance during smartphone reading in intermittent exotropia. Clin Ophthalmol 2018;12:2069-78.

11. Wang FM, Chryssanthou G. Monocular eye closure in intermittent exotropia. Arch Ophthalmol 1988;106:941-2.

12. Maconachie GD, Gottlob I, McLean RJ. Risk factors and genetics in common comitant strabismus: a systematic review of the literature. JAMA Ophthalmol 2013;131:1179-86.

13. Kushner BJ, Morton GV. Distance/near differences in intermittent exotropia. Arch Ophthalmol 1998;116:478-86.

14. Rosenbaum AL, Santiago AP. Clinical strabismus management: principles and surgical techniques. Philadelphia: Saunders; 1999. p. 17-165.

15. von Noorden GK, Campos EC. Examination of the patient. V. In: von Noorden GK, Campos EC. Binocular vision and ocular motility. St. Louis: Mosby; 2002. p. 298-307.

16. Nusz KJ, Mohney BG, Diehl NN. Female predominance in intermittent exotropia. Am J Ophthalmol 2005;140:546-7.

17. Govindan M, Mohney BG, Diehl NN, Burke JP. Incidence and types of childhood exotropia: a population-based study. Ophthalmology 2005;112:104-8. 
Supplement 1. Questionnaire form

\begin{tabular}{|c|c|}
\hline Questions & Please check the appropriate box. \\
\hline Who is answering this questionnaire? & $\square$ Patient (self) $\square$ Mother $\square$ Father $\square$ Grandparent $\square$ Etc. \\
\hline What is the reason for this visit? & Answer: \\
\hline Have you ever visited other clinics? & $\square$ No $\square$ Yes Name of the clinic: \\
\hline Have you ever noticed the ocular misalignment? & $\square$ Yes $\quad \square$ No $\quad \square$ Not sure \\
\hline $\begin{array}{l}\text { - Who noticed the symptom first? } \\
\text { (Example: parents, teacher, doctor etc.) }\end{array}$ & Answer: \\
\hline - When did you first notice the symptom? & Answer: $\quad$ years ago ( $\quad$ years of age $)$ \\
\hline How often in a day do you notice the symptom? & $\square$ None $\quad \square$ Less than once $\square$ Once or more \\
\hline What is the direction of the ocular misalignment? & $\begin{array}{l}\square \text { Inward } \square \text { Outward } \square \text { Upward } \\
\square \text { Not sure } \square \text { Etc.: }\end{array}$ \\
\hline Which eye do you think is misaligned? & $\begin{array}{l}\square \text { None } \square \text { Right } \square \text { Left } \square \text { Alternate } \\
\square \text { Not sure } \quad \square \text { Etc.: }\end{array}$ \\
\hline Have you ever noticed having an abnormal head posture? & $\begin{array}{l}\square \text { None } \quad \square \text { Tilt } \square \text { Head turn } \\
\square \text { Etc. }\end{array}$ \\
\hline How often do you notice the abnormal head posture? & $\square$ Always $\square$ Sometimes $\square$ Etc. \\
\hline Please select all of the symptoms which the patient presents. & $\begin{array}{l}\square \text { Frowning } \\
\square \text { Discomfort at near sight } \square \text { Headache } \\
\square \text { Ocular pain } \square \text { Visual blurring } \square \text { None } \square \text { Not sure } \\
\square \text { Things look smaller than they really are }\end{array}$ \\
\hline Any diplopia at near sight? & $\begin{array}{l}\square \text { None } \square \text { Not sure } \square \text { Less than once in a day } \\
\square \text { Once or more in a day }\end{array}$ \\
\hline Any diplopia at far sight? & $\begin{array}{l}\square \text { None } \square \text { Not sure } \square \text { Less than once in a day } \\
\square \text { Once or more in a day }\end{array}$ \\
\hline Has the patient ever received occlusion therapy? & $\square$ Yes $\square$ No \\
\hline - Prescribed period and duration? & Period: $\quad \sim \quad$ Duration in a day: \\
\hline - Which eye? & $\square$ Right $\quad \square$ Left $\quad \square$ Alternate \\
\hline - Real period and duration? & Period: __ $\quad \sim \quad$ Duration in a day: \\
\hline Does the patient wear the glasses? & $\square$ Never $\square$ Yes Since when: \\
\hline $\begin{array}{l}\text { Did the patient ever undergo any type of surgery } \\
\text { (including ocular surgery)? }\end{array}$ & $\square$ None $\square$ Yes Name of the surgery: \\
\hline $\begin{array}{l}\text { Has the patient ever been diagnosed with any medical } \\
\text { conditions? (Systemic disease, Developmental delay, ADHD, } \\
\text { Brain disease, etc.) }\end{array}$ & $\square$ None $\square$ Yes Diagnosis: \\
\hline Questions about birth history. & $\begin{array}{l}\square \text { Normal spontaneous vaginal delivery } \\
\square \text { Caesarean section } \quad \square \text { Not sure }\end{array}$ \\
\hline - Gestational age (weeks), birth weight (kg), prematurity? & Answer: ___ weeks __ \\
\hline $\begin{array}{l}\text { - Any problems at birth? (example: breathing difficulty, } \\
\text { lung disease, delivery complications) }\end{array}$ & $\square$ None $\square$ Yes Diagnosis: \\
\hline Does the patient's mother have any form of strabismus? & $\square$ No $\square$ Yes (Diagnosis: \\
\hline - Any strabismus surgery history? & $\square$ No $\square$ Yes $\square$ Not sure \\
\hline Does the patient's father have any form of strabismus? & $\square$ No $\square$ Yes (Diagnosis: \\
\hline - Any strabismus surgery history? & $\square$ No $\square$ Yes $\square$ Not sure \\
\hline Do the patient's siblings have any form of strabismus? & $\square$ No $\square$ Yes (Diagnosis: \\
\hline - Any strabismus surgery history? & $\square$ No $\square$ Yes $\square$ Not sure \\
\hline
\end{tabular}


Supplement 2. Examination form

- Best corrected visual acuity and cycloplegic refraction

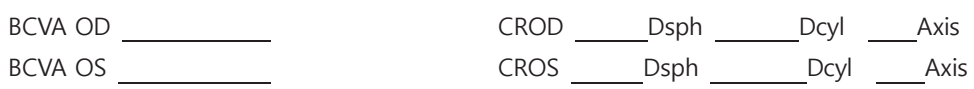

- Strabismus angle exam: after correction of refractive error as applicable. Please also indicate vertical deviation.

\begin{tabular}{|c|c|c|c|}
\hline Dsc & PD or Dcc & PD & Nsc \\
\hline
\end{tabular}

Fusion control :
at far sight $\square$ Good $\square$ Fair $\square$ Poor
Dominancy :

$$
\text { at far sight } \square \text { Good } \square \text { Fair } \square \text { Poor } \quad \text { at near sight } \square \text { Good } \square \text { Fair } \square \text { Poor }
$$

at far sight $\square$ Right $\square$ Left $\square$ Alternate $\quad$ at near sight $\square$ Right $\square$ Left $\square$ Alternate

References for the determination of fusion control

Good = no exotropia unless dissociated, recovery without blinking or refixating

Fair = no exotropia unless dissociated, recovery after blinking or refixating

Poor = exotropia before dissociation

If distant angle - near angle $\geq 10 P D$,

1) After 30 to 60 minutes of one eye occlusion,

\begin{tabular}{|c|c|c|c|c|}
\hline Nsc & PD & or & $\mathrm{Ncc}$ & PD \\
\hline Dsc & PD & or & Dcc & $P$ \\
\hline
\end{tabular}

- Strabismus angle at far sight

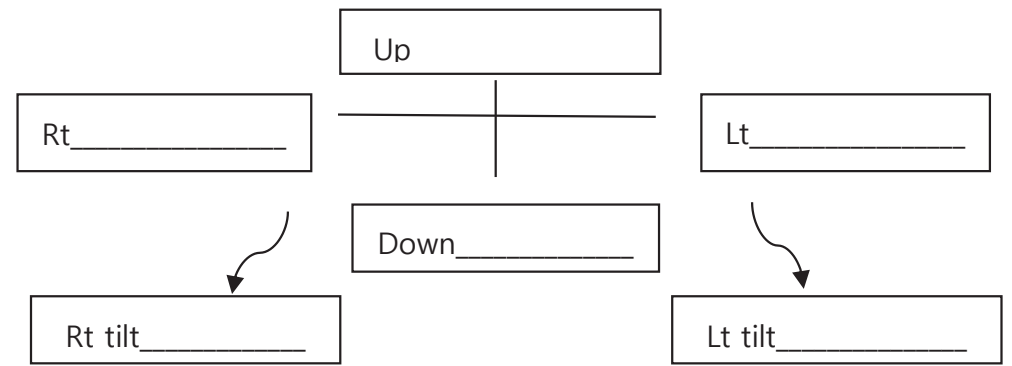

- Duction and Version: Please indicate the severity of the function of oblique muscles from -4 to +4 . (Refer to the standard photographs attached.)
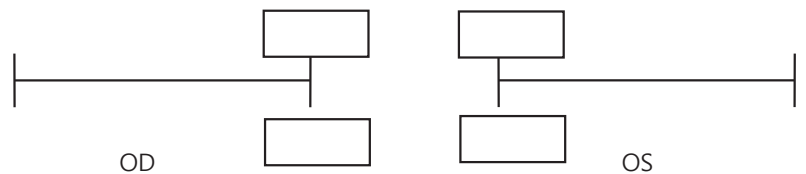

- Stereopsis

$$
\begin{array}{lrrr}
\text { Worth } 4 \text { Dot test (at far sight) } & \square 2 & \square 3 & \square 4 \quad \square 5 \\
\text { Titmus stereoacuity } & \text { fly }(-/+) \text { animal ( / 3) } & \operatorname{dot}(\text { / 9) } \\
\text { Or Randot stereoacuity } & \text { geometry }(+,-) \quad \operatorname{animal}(\text { / 3) }
\end{array}
$$

- Please indicate any treatments you recommend in this patients.

$\square$ Surgery: $\square$ BLR $\quad \square$ R\&R $\quad \square$ ULR $\square$ Etc. :

$\square$ Glasses:

$\square$ as CR $\square$ as MR/AR $\square$ Best corrected refraction $\square$ Overminus lens: $\quad \square \square$ Etc.:

$\square$ Occlusion: $\square$ Right $\square$ Left $\square$ Alternate R:L ratio( $\quad$ : )

$\square$ Less than 1 hour per day $\square 1 \sim 2$ hours per day $\square$ More than 2 hours per day

$\square$ Observation: months later $\quad \square$ Etc.: 